\title{
Rivastigmine prevents injury induced by ischemia and reperfusion in rat liver ${ }^{1}$
}

Agnaldo Bruno Chies', Paula Carolina Grande Nakazato", Maria Angélica Spadella"I, Patrícia Zorzi ${ }^{\mathrm{IV}}$, Maria Cecília Jordani Gomes`, Luiz Augusto Carneiro D’AlbuquerqueVI, Orlando Castro-e-SilvaVII

'PhD, Laboratory of Pharmacology, Marilia Medical School, Marilia-SP, Brazil. Conception and design of the study, analysis and interpretation of data, statistical analysis, manuscript writing.

"Graduate student, Marilia Medical School, Marilia-SP, Brazil. Conception and design of the study, technical procedures, acquisition of data.

I'PhD, Human Embryology Laboratory, Marilia Medical School, Marilia-SP, Brazil. Conception and design of the study, manuscript preparation.

IVGraduate student, Faculdade de Medicina de Ribeirao Preto, Universidade de São Paulo (FMRP-USP), Ribeirao Preto-SP, Brazil. Technical procedures, acquisition of data.

${ }^{\vee}$ Master, Biochemistry, Division of Digestive Surgery, Department of Surgery and Anatomy, FMRP-USP, Ribeirao Preto-SP, Brazil. Technical procedures; acquisition, analysis and interpretation of data; statistical analysis, critical revision.

V'PhD, Full Professor, Department of Gastroenterology, Sao Paulo Medical School, USP, Sao Paulo-SP, Brazil. Critical revision.

VIIPhD, Full Professor, Department of Surgery and Anatomy, Ribeirao Preto Medical School, and Department of Gastroenterology, Sao Paulo Medical School, USP. Conception and design of the study, analysis and interpretation of data, critical revision, final approval.

\section{Abstract}

Purpose: To evaluate whether pre-treatment with rivastigmine is able to attenuate the I/R induced lesions in rat liver.

Methods: SHAM animals or those submitted to $\mathrm{l} R$, non-treated or pre-treated with rivastigminine $(2 \mathrm{mg} / \mathrm{kg})$ either 50 or 15 minutes before ischemia, were used. After $1 / R$ protocol, these animals were killed and their livers were harvested to measurement of the mitochondrial swelling as well as the malondialdehyde (MDA), nitrite and nitrate tissue concentration. Blood was also harvested for serum aspartate aminotransferase (AST) and alanine aminotransferase (ALT) determinations.

Results: I/R promoted a significant increase of mitochondrial swelling in the studied animals. This increase of mitochondrial swelling was partially prevented by rivastigmine, but only if administered 50 minutes before ischemia. No significant modification of MDA, nitrite or nitrate tissue concentrations was observed in consequence of $I / R$, followed or not by rivastigmine treatments. In addition, I/R elevated both AST and ALT. These elevations of serum enzymes were not reversed by the different rivastigmine treatments.

Conclusions: Rivastigmine administered 50 minutes before ischemia attenuates I/R-induced mitochondrial swelling, that indicates liver injury. This protective effect may be related to a greater stimulation of $\alpha 7 n A C h R$ present in the Kupffer cells by the non-methabolized ACh, leading to an attenuation of I/R-induced inflammation.

Key words: Rivastigmine. Mitochondria. Liver. Ischemia. Reperfusion. Rats. 


\section{Introduction}

Lasting hepatic ischemia, which usually occurs in liver transplants, in large partial hepatectomies or in hemorrhagic shocks, can trigger a series of cellular changes that can lead to tissue death ${ }^{1}$. Actually, lack of oxygen due to absence or reduction of tissue blood supply immediately interrupts the flow of electrons in the respiratory chain of mitochondria, thereby inhibiting oxidative phosphorylation. This process leads to reduction of the synthesis of adenosine triphosphate (ATP). Lacking ATP, the glycolysis is accelerated which increases the lactate synthesis and reduces the $\mathrm{pH}$ in the intracellular environment ${ }^{2,3}$. In addition, the $\mathrm{Na}^{+} / \mathrm{K}^{+}$ATPase inhibition affects the ions transmembrane transport, resulting in intracellular $\mathrm{Na}^{+}$and $\mathrm{Ca}^{2+}$ accumulation, which can cause cell death ${ }^{3,4}$.

Paradoxically, the cellular changes initiated by ischemia are aggravated after restoration of blood flow. This is because, in reperfusion, the oxygen reintroduction into ischemic tissue leads to the generation of reactive oxygen species (ROS), with mitochondria being the largest source of free radicals in liver cells ${ }^{5}$. Actually, the process of oxidative phosphorylation is severely affected in the reperfusion period, since the respiratory chain is located in the internal mitochondrial membrane, where ROS act importantly. These changes increase the internal mitochondrial membrane permeability, a phenomenon named transition of mitochondrial permeability (MPT), resulting thus in the mitochondrial swelling ${ }^{3,6}$. MPT is aggravated by high $\mathrm{Ca}^{2+}$ concentrations and intracellular $\mathrm{pH}$ reduction and its occurrence marks the irreversibility of cellular damage ${ }^{7}$. This process described as ischemia and reperfusion injury $(\mathrm{I} / \mathrm{R})$, although widely studied, involves pathophysiological mechanisms that still need to be better known ${ }^{1,8,9}$.

In reperfusion, besides the metabolic disorder and the oxidative stress caused by high concentration of ROS, there is involvement of local inflammatory response. Damageassociated molecular patterns (DAMPs) that are released by hepatic tissue injured in the ischemia, act on Toll-like receptors present on cells of the immune system, mainly in the Kupffer cells (KCs), thereby releasing of several pro-inflammatory cytokines such as tumor necrosis factor (TNF- $\alpha$ ), interleukin-1 $\beta$ (IL-1 $\beta$ ), interferon-gamma (INF- $\gamma$ ), among others ${ }^{10,11}$. High concentrations of reactive oxygen species can also activate the $\mathrm{KCs}{ }^{11,12}$.

Considering the importance of the inflammatory response in $\mathrm{l} / \mathrm{R}$-induced liver damage, drugs that inhibit cells of the immune system are considered attractive therapeutic alternatives to prevent such lesions. In this context, it has been shown that acetylcholine (ACh) released from nerve fibers may have anti-inflammatory effects inasmuch as it suppresses cells of the immune system through activation of $\alpha 7$ nicotinic acetylcholine receptor ( $\alpha 7 n A C h R)$. In fact, stimulation of $\alpha 7 n A C h R$ activates intracellular signaling pathways that culminate in the inhibition of NF-k $\beta$ factor in immune cells, thereby suppressing the release of proinflammatory cytokines ${ }^{13,14}$. This mechanism has been referred to in the literature as "cholinergic anti-inflammatory pathway".

The therapeutic potential of cholinergic anti-inflammatory pathway in the prevention of $\mathrm{I} / \mathrm{R}$ lesions has already been investigated in liver of animals. Pre-treatment of mice with PNU-282987, an $\alpha 7 n A C h R$ selective agonist, suppressed the production of TNF- $\alpha$ and IL-1 $\beta$ and the expression of high-mobility group box 1 protein (HMGB1) as well as decreased the serum transaminase levels and reduced the I/R-induced hepatic injury ${ }^{15}$. In addition, it was proposed that the vagus nerve could minimize I/R-induced liver apoptosis in mice through activating $\alpha 7 n A C h R$ on KCs possibly by preventing their excessive ROS production ${ }^{16}$. Activation of $\alpha 7 n A C h R$ by nicotine may also prevent the hepatic injury induced by $\mathrm{I} / \mathrm{R}$. This protection may be due 
to inhibition of the inflammatory response through HO-1 induction ${ }^{17}$.

Activation of the cholinergic antiinflammatory pathway can be done by the use of $\alpha 7 n A C h R$ receptor agonists or by vagal stimulation. This pathway can also be stimulated through the inhibition of ACh degradation by acetylcholinesterase (AChE) inhibitors ${ }^{18,19}$. By increasing the concentration of $\mathrm{ACh}$, these drugs may increase the stimulation of $\alpha 7 n A C h R$ in the immune system cells. Anti-inflammatory actions of AChE inhibitors were observed in animal models of arthritis ${ }^{20}$. Thus, rivastigmine, an AChE inhibitor used for the symptomatic treatment of Alzheimer's Disease, may be an interesting alternative for the prevention of $\mathrm{I} / \mathrm{R}$ lesions because. Thus, the present study aimed to verify if pre-treatment with rivastigmine is able to attenuate the $I / R$ induced lesions in rat liver.

\section{- Methods}

This study was approved by the institution's Animal Experimentation Ethics Committee (CEUA/ FMRP-USP, protocol number 14/2006).

Twenty-five male Wistar rats ( 8 to 9 weeks of age) were used. These rats were maintained in the animal facilities of FMRP-USP under standard laboratory conditions $\left(23^{\circ} \mathrm{C} \pm\right.$ $1^{\circ} \mathrm{C}, 12$-hour light/dark cycle), with free access to water and pelleted rodent chow.

\section{Experimental groups}

Animals were distributed into 4 groups of 6-7 animals: SHAM - rats subjected to surgical and anesthetic stress with no clamping of the hepatic pedicle during $75 \mathrm{~min}$; I/R - rats submitted to 60 min of ischemia followed by 15 min of reperfusion; Riv50-I/R - rats submitted to $60 \mathrm{~min}$ of ischemia followed by $15 \mathrm{~min}$ of reperfusion and treated with rivastigmine ( $2 \mathrm{mg} / \mathrm{kg}$, intraperitoneally), $50 \mathrm{~min}$ before of the ischemia; Riv15-I/R - rats submitted to $60 \mathrm{~min}$ of ischemia followed by $15 \mathrm{~min}$ of reperfusion and treated with rivastigmine ( $2 \mathrm{mg} / \mathrm{kg}$, intraperitoneally), $15 \mathrm{~min}$ before of the ischemia. The number of animals in each group was established based on Maxwell et al. ${ }^{21}$

\section{Surgical technique}

The animals were anesthetized by intramuscular injection $(0.2 \mathrm{~mL} / 100 \mathrm{~g}$ of body weight) of a solution of $2 \%$ xylazine hydrochloride and $10 \%$ ketamine hydrochloride, in a ratio of 1:2. Following trichotomy, a median laparotomy was performed to exposure the liver, after dissection of the round and falciform ligaments. The hepatic pedicle was fully clamped with an aneurism clamp for 60 minutes, followed by reperfusion for 15 minutes (after clamp removing), in a cycle that lasted 75 minutes. After, the animals were killed by exsanguination. The blood was collected by puncture of the inferior vena cava for dosages of serum alanine aminotransferase (ALT) and aspartate aminotransferase (AST). Hepatic tissues were harvested for isolation of the mitochondria required to the study of mitochondrial osmotic swelling. Part of the harvested hepatic tissue samples were frozen at $-70^{\circ} \mathrm{C}$ for determination of malondialdehyde (MDA) and nitrite and nitrate.

\section{Mitochondrial preparation}

Mitochondria content of the liver were isolated by differential centrifugation at $4^{\circ} \mathrm{C}$. After the surgical procedure, the livers were immediately removed and washed in saline solution. Then, they were placed in medium containing $250 \mathrm{mM}$ sucrose, $1 \mathrm{mM}$ EGTA and $10 \mathrm{mM}$ Hepes- $\mathrm{KOH}$, in $\mathrm{pH} \mathrm{7.2,} \mathrm{cut} \mathrm{in} \mathrm{small}$ pieces and homogenized in Potter-Elvehjem for 3 cycles of 15 seconds with an interval of $1 \mathrm{~min}$. The homogenate was centrifuged at $770 \mathrm{~g}$ for $5 \mathrm{~min}$ and the resulting supernatant was centrifuged at $9800 \mathrm{~g}$ for $10 \mathrm{~min}$. The pellet was suspended in $10 \mathrm{~mL}$ of medium containing 
$250 \mathrm{mM}$ sucrose, $0.3 \mathrm{mM}$ EGTA and $10 \mathrm{mM}$ Hepes- $\mathrm{KOH}, \mathrm{pH} \mathrm{7.2,} \mathrm{and} \mathrm{centrifuged} \mathrm{at} 4500$ $\mathrm{g}$ for $15 \mathrm{~min}$. The final pellet containing the isolated of mitochondria was suspended in $0.5 \mathrm{~mL}$ of medium containing $250 \mathrm{mM}$ sucrose and $10 \mathrm{mM}$ Hepes- $\mathrm{KOH} \mathrm{pH} 7.2^{22}$. In parallel, mitochondrial proteins were determined by coomassie (Coomassie plus kit - Bradford Assay) at $595 \mathrm{~nm}$ in a Versamax microplate reader (Molecular Devices). The results were expressed as $\mathrm{mg} / \mathrm{ml}$ using bovine serum albumin as standard.

\section{Mitocondrial swelling}

The repercussions of $I / R$ on hepatic tissues were estimated by quantification of internal mitochondrial membrane permeability, based on mitochondrial swelling related to $\mathrm{Ca}^{+2}$ homeostasis. Thus, the isolated of mitochondria obtained was challenge by $20 \mu \mathrm{M}$ calcium chloride and $1 \mathrm{mM}$ potassium phosphate. The absorbance variation was determined at $540 \mathrm{~nm}$, using a Beckman DU-640B spectrophotometer, by the optical density $(\triangle D O)$. Data obtained were interpreted as follows: lower variation of $\triangle \mathrm{DO}$ indicates that the permeability of the mitochondrial membrane is already increased, denoting the presence of mitochondrial swelling. Thus, the challenge with calcium chloride and potassium phosphate hardly modifies its permeability ${ }^{23}$.

\section{MDA determination}

The colorimetric determination of MDA by its reaction with thiobarbituric acid was carried out at $532 \mathrm{~nm}$ in a Versamax microplate reader (Molecular Devices), using 1,1,3,3-tetramethoxypropane (0 to $100 \mu \mathrm{M}$ ) as a standard ${ }^{24}$.

\section{Nitrite and nitrate determination}

Nitric oxide (NO) determination was performed by chemiluminescence in a Sievers
NO Analyzer (GE Analytical Instruments). The nitrate concentration was determined by injecting $15 \mu \mathrm{L}$ of the deproteinized liver homogenate into a reaction chamber containing $0.8 \%$ vanadium chloride in $1 \mathrm{~N}$ cloridric acid at $95^{\circ} \mathrm{C}$. The results obtained were expressed in $\mu \mathrm{M} / \mathrm{mg}$ protein, calculated from a standard curve of sodium nitrate in concentrations of 2.5 to $50 \mu \mathrm{M}$.

The nitrite concentration was determined using $100 \mu \mathrm{L}$ of deproteinized liver homogenate and was carried out in a similar manner to that described above, with the presence of a solution of acidified iodine $(2 \mathrm{~g}$ potassium iodide plus $1.3 \mathrm{~g}$ iodine dissolved in $40 \mathrm{~mL}$ of water plus $140 \mathrm{~mL}$ of acetic acid) in the reaction chamber. This solution reduces only nitrite to NO. The concentration of nitrite was calculated through a curve of sodium nitrite $(2$ to $0.1 \mu \mathrm{M})$ as standard. The results were expressed as $\mu \mathrm{M} / \mathrm{mg}$ protein.

\section{ALT and AST determination}

The aminotransferases were determined by the kinetic method at $340 \mathrm{~nm}$, with the CELM SB-190 device, using the Labtest ${ }^{\circ}$ kit.

\section{Statistical analysis}

The normality of the data was verified by the Shapiro-Wilk test and the homogeneity of variances by the Levene test. To parametric data, means \pm standard deviation (SD) were compared by Anova-one-way, followed by the Bonferroni post-Hoc test. In the cases that the normality of the data and the homogeneity of variances were violated, the comparisons were performed by Kruskal-Wallis non-parametric test and values expressed as median (with minimum and maximum values). The pairto-pair comparisons were performed by the Mann-Whitney non-parametric test, with critical values of $P$ adjusted by Holm-Sidak post hoc correction ( $\mathrm{P} \leq 0.012)$. For multivariate analysis, values of $p<0.05$ were considered 
statistically significant. All data analyses were performed using SPSS ${ }^{\circ}$ software, version 19.0.

\section{Results}

The data obtained show that I/R promoted a significant increase of mitochondrial swelling in the studied animals. This increase in I/R-induced mitochondrial swelling was partially reversed by rivastigmine, if administered 50 minutes before discontinuation of blood flow. On the other hand, the increase in mitochondrial swelling caused by I/R was not influenced by pre-treatment with rivastigmine, if done 15 minutes before the interruption of blood flow (Figure 1).

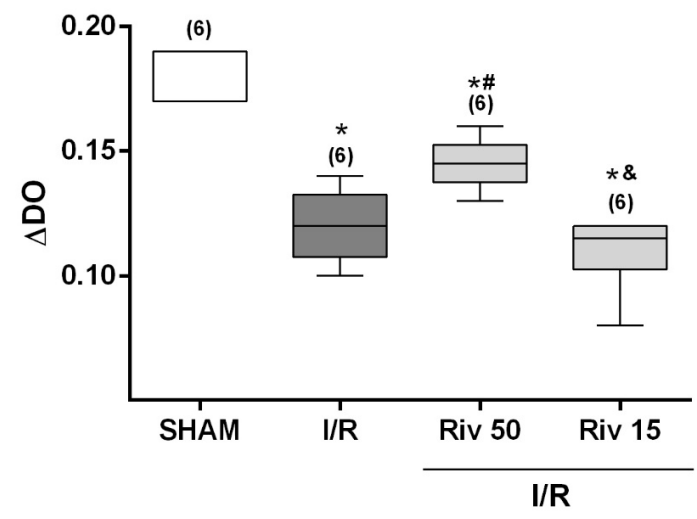

Figure 1 - Variation of inner mitochondrial membrane permeability (indicative of mitocondrial swelling) determined in animals SHAM or subjected to ischemia for 60 minutes, followed by reperfusion of 15 minutes, studied without any pharmacological treatment $(\mathrm{I} / \mathrm{R})$ or treated with rivastigmine (2mg/kg, intraperitonially), 50 minutes (Riv 50) or 15 minutes (Riv15) prior to ischemia. Values expressed in median (with minimum and maximum values). In parentheses, number of independent determinations. * Significant difference in relation to the SHAM animals; \# significant difference in relation to the I/R animals; \& significant difference in relation to the Riv50 animals. Comparisons between the groups by the Kruskall-Wallis test, followed by pair-to-pair comparisons by the MannWhitney test, with critical values of $P$ adjusted by Holm-Sidak post hoc correction.
Although MDA values increased in the I/R group and reduced in the Riv15 group, none of these modifications was statistically significant (Figure 2). The concentrations of nitrite and nitrate were also not significantly modified by the treatments to which the animals were exposed (Table 1).

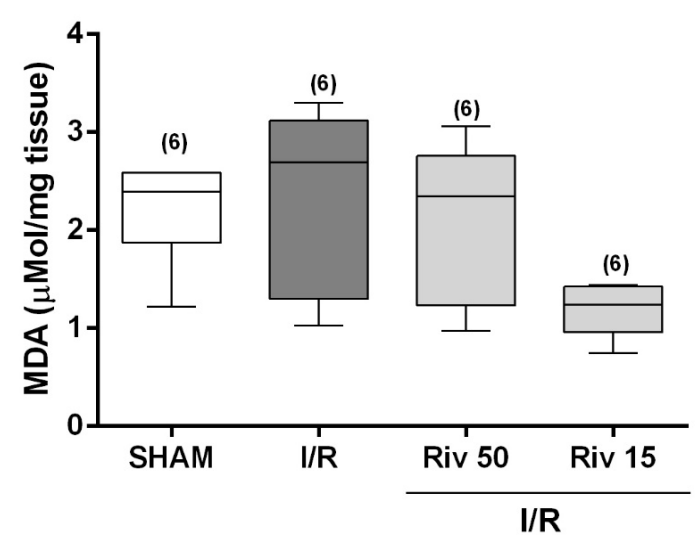

Figure 2 - Malondialdeido (MDA) concentrations determined in animals SHAM or subjected to ischemia for 60 minutes, followed by reperfusion of 15 minutes, studied without any pharmacological treatment $(\mathrm{I} / \mathrm{R})$ or treated with rivastigmine (2mg/kg, intraperitonially), 50 minutes (Riv 50) or 15 minutes (Riv15) prior to ischemia. Values expressed in median (with minimum and maximum values). In parentheses, number of independent determinations. Comparisons between the groups by the Kruskall-Wallis test, followed by pair-topair comparisons by the Mann-Whitney test, with critical values of $\mathrm{P}$ adjusted by Holm-Sidak post hoc correction. 
Table 1 - Nitrite and nitrate concentrations among the experimental groups.

\begin{tabular}{ccccc}
\hline $\begin{array}{c}\text { Parameters } \\
(\boldsymbol{\mu M o l} / \text { mg protein) }\end{array}$ & SHAM & I/R & Riv50-I/R & Riv15-I/R \\
\hline Nitrite & $2.44 \pm 0.90$ & $3.68 \pm 1.37$ & $2.50 \pm 1.13$ & $3.24 \pm 0.18$ \\
& $(n=6)$ & $(n=6)$ & $(n=6)$ & $(n=6)$ \\
Nitrate & $0.62 \pm 0.23$ & $1.19 \pm 0.55$ & $0.70 \pm 0.40$ & $0.75 \pm 0.31$ \\
& $(n=6)$ & $(n=6)$ & $(n=6)$ & $(n=6)$ \\
\hline
\end{tabular}

Values expressed in means \pm SD.

Comparisons between the groups by One-way Variance Analysis (ANOVA), followed by the Bonferroni test.

$n=$ number of independent determinations.

I/R significantly elevated serum AST concentrations. Treatment with rivastigmine, 50 minutes before ischemia, did not reverse this elevation of AST. On the other hand, when animals submitted to $\mathrm{I} / \mathrm{R}$ were treated with rivastigmine, 15 minutes before interruption of blood flow, the AST elevation was even higher. Similarly, I/R raised serum ALT concentrations and the treatments with rivastigmine at both pre-ischemia times were not able to reverse these changes (Figure 3).
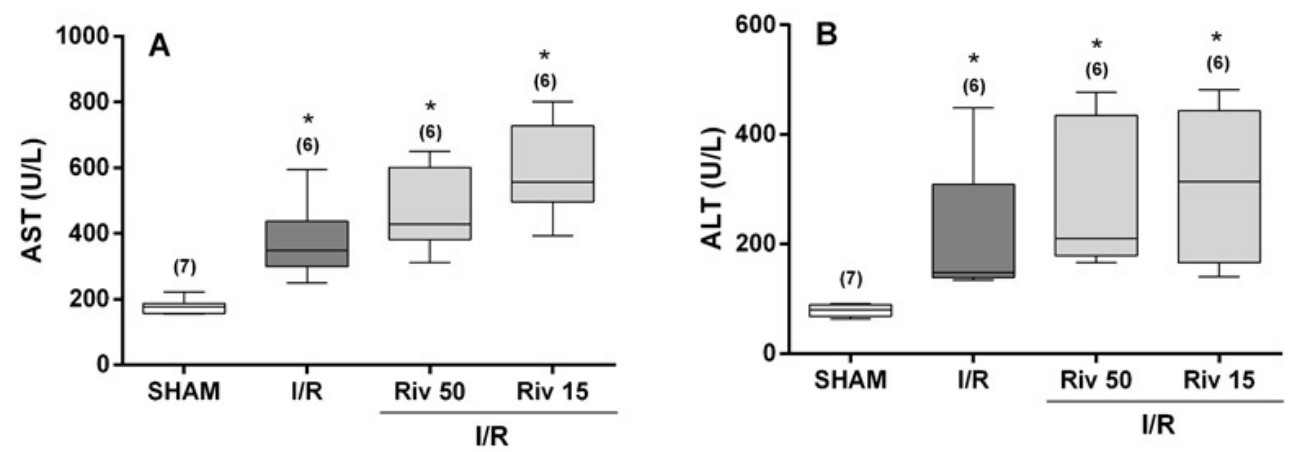

Figure 3 - Serum concentrations of aspartate aminotrasferase (AST; A) and alanine aminotransferase (B; AST) determined in animals SHAM or subjected to ischemia for 60 minutes, followed by reperfusion of 15 minutes, studied without any pharmacological treatment (I/R) or treated with rivastigmine $(2 \mathrm{mg} / \mathrm{kg}$, intraperitonially), 50 minutes (Riv 50) or 15 minutes (Riv15) prior to ischemia. Values expressed in median (with minimum and maximum values). In parentheses, number of independent determinations. * Significant differences in relation to SHAM animals. Comparisons between the groups by the Kruskall-Wallis test, followed by pairto-pair comparisons by the Mann-Whitney test, with critical values of $\mathrm{P}$ adjusted by Holm-Sidak post hoc correction.

\section{- Discussion}

In the present study, the repercussions of $\mathrm{I} / \mathrm{R}$ on hepatic tissue were assessed by mitochondrial swelling. This is a fundamental parameter in the present study since it indicates mitochondrial dysfunction, one of the central pathophysiological events of $1 / R$ injury ${ }^{3,6}$. In this sense, the increment in the mitochondrial swelling observed in the livers submitted to $\mathrm{I} / \mathrm{R}$ indicates that the protocol used was effective and promoted the lesions under investigation.

Once the experimental model was effective, it was possible to evaluate the effects 
of pre-treatment with rivastigmine on the I/Rinduced lesions in the livers of the studied animals. Considering that the peak of AChE inhibition by rivastigmine occurs around 50 minutes $^{25}$, a group of animals was treated 50 minutes before the interruption of blood flow. Thus, in these animals, AChE blockade was already established during ischemia. Another group of animals was treated 15 minutes prior to ischemia, so that the effects of rivastigmine on AChE predominated in the reperfusion phase. The obtained data showed that the treatment with rivastigmine done 50 minutes before interruption of blood flow partially reversed the increment in mitochondrial swelling due to I/R. Treatment done 15 minutes before ischemia had no protective effect. These data suggest that rivastigmine, possibly potentiating the action of cholinergic anti-inflammatory pathway by inhibiting AChE, may attenuate I/R-induced damage in liver. However, for this action to occur, the AChE inhibition must be established in the ischemia phase. It should be noted that in this phase the first cellular lesions occur, with the release of DAMPs $^{11}$. Apparently, early modulation upon $\mathrm{KCs}$, already in the ischemia phase, is more likely to protect hepatic cells submitted to I/R.

It has been proposed that the reduction of tissue oxygenation due to ischemia interrupts the respiratory chain in the internal mitochondrial membrane, leading to the production of ROS, mainly when the blood flow is reestablished during reperfusion ${ }^{11}$. In fact, high concentrations of ROS in tissues exposed to I/R lead to peroxidation of lipid cellular structures ${ }^{26}$. Thus, the quantification of lipoperoxides in these tissues may indicate the degree of oxidative stress imposed by I/R. In this regard, previous animal studies have shown that livers submitted to $I / R$ present elevation of MDA, a final product of lipoperoxidation ${ }^{27,28}$. The tissue MDA, which indicates the degree of oxidative stress, increased in the I/R group, but this increment was not statistically significant. Although not statistically significant, this increment of MDA suggests that tissue concentrations of ROS are higher in livers exposed to I/R, which may lead to activation of $\mathrm{KCs}^{11}$. At the same time, the inflammatory response resulting from KCs activation may lead to increased ROS generation and further aggravate local oxidative stress ${ }^{26}$. Assuming that this elevation of oxidative stress in livers submitted to I/R has existed, a certain protective effect of rivastigmine is evident, especially when administered 15 minutes before ischemia. This suggests that rivastigmine, especially in the reperfusion phase, may have suppressed KCs and, therefore, the inflammatory response triggered by $\mathrm{I} / \mathrm{R}$.

I/R may also influence the local bioavailability of nitric oxide (NO). However, the role of $\mathrm{NO}$ in I/R is a bit more puzzling. $\mathrm{NO}$ is produced by three isoforms of nitric oxide synthases (NOS), endothelial (eNOS), neuronal (nNOS) and inducible (iNOS) ${ }^{29}$. It has been proposed that NO production by eNOS, a constitutively expressed enzyme in the hepatic vascular territory, has protective effects against damage caused by I/R. On the other hand, the inflammatory process inherent to I/R can promote an increase in the presence of iNOS in the liver and, consequently, a massive production of NO, with unpredictable effects on this organ ${ }^{30}$. In the present study, the tissue concentrations of nitrite and nitrate, both NO products, were quantified. It was observed that the I/R did not significantly modify the concentration of these NO metabolites in the studied livers. Similarly, no I/R-induced modification of nitrite and nitrate was observed in animals treated with rivastigmine. Although no significant change has been observed, I/R-induced changes in the NO production cannot be ruled out in the studied livers. The obtained data show a tendency of elevation in 
the concentrations of both nitrite and nitrate, which may indicate that differences can occur if the ischemia and/or the reperfusion are prolonged. If this is true, it is worth noting that these trends of increment in nitrite and nitrate concentrations were completely blunted in the presence of rivastigmine. However, in order to know the effects of rivastigmine on these parameters, other experimental protocols are necessary.

The here presented data suggest that rivastigmine attenuates, at least partially, the I/R-induced hepatic injuries. Thus, it is corroborated the hypothesis that rivastigmine, by blocking the degradation of $\mathrm{ACh}$, suppresses the inflammatory response due to the I/R. This action probably culminates in the stimulation of $\alpha 7 n A C h R$ present in the KCs. This information, naturally, may rise a big clinical interest because it may contribute to the expansion of the therapeutic arsenal for the treatment of $I / R$, which so much impacts the success of liver transplants. However, the data also showed that rivastigmine treatments did not reverse ALT and AST elevations. This suggests that rivastigime, at least at that dose, may not be the best AChE inhibitor to be used in order to prevent the I/R-induced liver damage. Indeed, because it was a pioneering study, it was decided to use high doses of rivastigmine $(2 \mathrm{mg} / \mathrm{kg}$ ) in order to ensure complete blockade of AChE in these animals ${ }^{25}$. These results, although unfavorable, does not diminish the relevance of the present study since the protective mechanism related to AChE blockade was verifyied. However, other experimental approaches, with the use of other AChE inhibitors, in different doses, are needed in order to validate this apparently promising therapeutic resource.

\section{Conclusions}

The treatment with rivastigmine performed 50 minutes before ischemia attenuates I/R-induced mitochondrial swelling, that indicates liver injury. This protective effect may be related to a greater stimulation of $\alpha 7 n A C h R$ present in the KCs by the nonmethabolized $\mathrm{ACh}$, leading to an attenuation of the inflammatory response due to l/R. However, further studies are needed to substantiate this hypothesis and to provide support for the use of AChE inhibitors in the prevention of I/Rinduced hepatic injury.

\section{References}

1. Castro e Silva Jr O, Centurion S, Pacheco EG, Brisotti JL, Oliveira AF, Dal Sasso K. Aspectos básicos da lesão de isquemia e reperfusão e do pré-condicionamento isquêmico. Acta Cir Bras. 2002;17:5.2. doi: 10.1590/S010286502002000900020.

2. Jaeschke H. Molecular mechanisms of hepatic ischemia-reperfusion injury and preconditioning. Am J Physiol Gastrointest Liver Physiol. 2003;284(1):G15-26. doi: 10.1152/ajpgi.00342.2002.

3. Peralta C, Jimenez-Castro MB, GraciaSancho J. Hepatic ischemia and reperfusion injury: effects on the liver sinusoidal milieu. J Hepatol. 2013;59(5):1094-106. doi: 10.1016/j.jhep.2013.06.017.

4. Ramalho FS, Fernandez-Monteiro I, RoselloCatafau J, Peralta C. Hepatic microcirculatory failure. Acta Cir Bras. 2006;21 Suppl 1:48-53. doi: 10.1590/S0102-86502006000700012.

5. Caraceni $P$, Domenicali $M$, Vendemiale G, Grattagliano I, Pertosa A, Nardo B, Morselli-Labate AM, Trevisani F, Palasciano $G$, Altomare $E$, Bernardi $M$. The reduced tolerance of rat fatty liver to ischemia reperfusion is associated with mitochondrial oxidative injury. J Surg Res. 2005;124(2):1608. doi: 10.1016/j.jss.2004.10.007.

6. Caldeira DE, Souza ME, Gomes MC, Picinato MA, Fina CF, Feres O, Castro e Silva $O$. Effects of hyperbaric oxygen (HBO), as preconditioning in liver of rats submitted to periodic liver ischemia/reperfusion. Acta Cir Bras. 2013;28 Suppl 1:66-71. doi: 10.1590/ S0102-86502013001300013.

7. Martins RM, Teodoro JS, Furtado E, Rolo AP, Palmeira CM, Tralhao JG. Recent insights into mitochondrial targeting strategies in liver transplantation. Int J 
Med Sci. 2018;15(3):248-56. doi: 10.7150/ ijms.22891.

8. Montalvo-Jave EE, Escalante-Tattersfield T, Ortega-Salgado JA, Pina E, Geller DA. Factors in the pathophysiology of the liver ischemia-reperfusion injury. J Surg Res. 2008;147(1):153-9. doi: 10.1016/j. jss.2007.06.015.

9. Cannistra M, Ruggiero M, Zullo A, Gallelli G, Serafini S, Maria M, Naso A, Grande R, Serra $R$, Nardo B. Hepatic ischemia reperfusion injury: A systematic review of literature and the role of current drugs and biomarkers. Int J Surg. 2016;33 Suppl 1:S57-70. doi: 10.1016/j.ijsu.2016.05.050.

10.Tsung A, Sahai $R$, Tanaka $H$, Nakao A, Fink MP, Lotze MT, Yang $\mathrm{H}$, Li J, Tracey KJ, Geller DA, Billiar TR. The nuclear factor HMGB1 mediates hepatic injury after murine liver ischemia-reperfusion. J Exp Med. 2005;201(7):1135-43. doi: 10.1084/ jem.20042614.

11.Lu TF, Yang TH, Zhong CP, Shen C, Lin WW, Gu GX, Xia Q, Xu N. Dual effect of hepatic macrophages on liver ischemia and reperfusion injury during liver transplantation. Immune Netw. 2018;18(3):e24. doi: 10.4110/in.2018.18. e24.

12. Hou J, Xia Y, Jiang R, Chen D, Xu J, Deng L, Huang $X$, Wang $X$, Sun B. PTPRO plays a dual role in hepatic ischemia reperfusion injury through feedback activation of NF-kappaB. J Hepatol. 2014;60(2):306-12. doi: 10.1016/j. jhep.2013.09.028.

13.Baez-Pagan CA, Delgado-Velez $M$, LasaldeDominicci JA. Activation of the Macrophage alpha7 Nicotinic Acetylcholine Receptor and Control of Inflammation. J Neuroimmune Pharmacol. 2015;10(3):468-76. doi: 10.1007/s11481-015-9601-5.

14.Ren C, Tong YL, Li JC, Lu ZQ, Yao YM. The protective effect of alpha 7 nicotinic acetylcholine receptor activation on critical illness and its mechanism. Int J Biol Sci. 2017;13(1):46-56. doi: 10.7150/ijbs.16404.

15.Li F, Chen Z, Pan Q, Fu S, Lin F, Ren H, Han $H$, Billiar TR, Sun F, Li Q. The protective effect of PNU-282987, a selective alpha7 nicotinic acetylcholine receptor agonist, on the hepatic ischemia-reperfusion injury is associated with the inhibition of highmobility group box 1 protein expression and nuclear factor kappaB activation in mice. Shock. 2013;39(2):197-203. doi: 10.1097/ SHK.0b013e31827aa1f6.

16.Ni M, Fu H, Huang F, Zhao T, Chen JK, Li DJ, Shen FM. Vagus nerve attenuates hepatocyte apoptosis upon ischemia-reperfusion via alpha 7 nicotinic acetylcholine receptor on Kupffer cells in mice. Anesthesiology. 2016;125(5):1005-16. doi: 10.1097/ ALN.0000000000001309.

17.Park J, Kang JW, Lee SM. Activation of the cholinergic anti-inflammatory pathway by nicotine attenuates hepatic ischemia/ reperfusion injury via heme oxygenase-1 induction. Eur J Pharmacol. 2013;707(13):61-70. doi: 10.1016/j.ejphar.2013.03.026. 18.Nizri $E$, Irony-Tur-Sinai $M$, Faranesh $N$, Lavon I, Lavi E, Weinstock M, Brenner T. Suppression of neuroinflammation and immunomodulation by the acetylcholinesterase inhibitor rivastigmine. J Neuroimmunol. 2008;203(1):12-22. doi: 10.1016/j.jneuroim.2008.06.018.

19. Anand P, Singh B. A review on cholinesterase inhibitors for Alzheimer's disease. Arch Pharm Res. 2013;36(4):375-99. doi: 10.1007/s12272-013-0036-3.

20.Gowayed MA, Refaat R, Ahmed WM, ElAbhar HS. Effect of galantamine on adjuvantinduced arthritis in rats. Eur J Pharmacol. 2015;764:547-53. doi: 10.1016/j. ejphar.2015.07.038.

21. Maxwell SE, Kelley K, Rausch JR. Sample size planning for statistical power and accuracy in parameter estimation. Ann Rev Psychol. 2008;59:537-63. doi: 10.1146/annurev. psych.59.103006.093735.

22.Pedersen PL, Greenawalt JW, Reynafarje B, Hullihen J, Decker GL, Soper JW, Bustamente E. Preparation and characterization of mitochondria and submitochondrial particles of rat liver and liver-derived tissues. Methods Cell Biol. 1978;20:411-81. PMID: 151184.

23.Zoratti M, Szabo I. The mitochondrial permeability transition. Biochim Biophys Acta. 1995;1241(2):139-76. PMID: 7640294.

24.Lapenna D, Ciofani G, Pierdomenico SD, Giamberardino MA, Cuccurullo F. Reaction conditions affecting the relationship between thiobarbituric acid reactivity and lipid peroxides in human plasma. Free Radic Biol Med. 2001;31(3):331-5. doi: 10.1016/ 
S0891-5849(01)00584-6.

25.Wang RH, Bejar C, Weinstock M. Gender differences in the effect of rivastigmine on brain cholinesterase activity and cognitive function in rats. Neuropharmacology. 2000;39(3):497-506. doi: 10.1016/S00283908(99)00157-4.

26.Granger DN, Kvietys PR. Reperfusion injury and reactive oxygen species: The evolution of a concept. Redox Biol. 2015;6:524-51. doi: 10.1016/j.redox.2015.08.020.

27.Losada DM, Chies AB, Feres O, Chaib E, D’Albuquerque LA, Castro-e-Silva O. Effects of hyperbaric oxygen therapy as hepatic preconditioning in rats submitted to hepatic ischemia/reperfusion injury. Acta Cir Bras. 2014;29 Suppl 2:61-6. doi: 10.1590/S01028650201400140012.
28. Losada DM, Jordani ME, JordaniMC, Piccinato $M A$, Fina $C F$, Feres $O$, Chies $A B$, Evora PR, de Castro E Silva O. Should preconditioning hyperbaric oxygenation protect the liver against ischemia-reperfusion injury? An experimental study in a rat model. Transplant Proc. 2014;46(1):56-62. doi: 10.1016/j.transproceed.2013.10.044.

29.Forstermann U, Sessa WC. Nitric oxide synthases: regulation and function. Eur Heart J. 2012;33(7):829-37, 837a-837d. doi: 10.1093/eurheartj/ehr304.

30.Atef Y, El-Fayoumi HM, Abdel-Mottaleb $Y$, Mahmoud MF. Effect of cardamonin on hepatic ischemia reperfusion induced in rats: role of nitric oxide. Eur J Pharmacol. 2017;815:446-53. doi: 10.1016/j. ejphar.2017.09.037.

\section{Correspondence:}

Agnaldo Bruno Chies

Faculdade de Medicina de Marília, Disciplina

de Farmacologia

Avenida Monte Carmelo, 800

17.519-030 Marília - SP Brasil

Tel.: (55 14)3402-1726

agnaldochies@hotmail.com

Received: May 28, 2018

Review: July 25, 2018

Accepted: Aug 23, 2018
Conflict of interest: none

Financial sources: FAPESP, CAPES, and CNPq
${ }^{1}$ Research performed at Department of Surgery and Anatomy, Ribeirao Preto Medical School, and Department of Gastroenterology, Sao Paulo Medical School, Universidade de São Paulo (USP), Brazil. 